\title{
Influence of substrate temperature parameter on electrospinning process: example of application to the formation of gelatin fibers
}

\author{
Reda Morsy ${ }^{1}$
}

Received: 30 October 2021 / Revised: 17 January 2022 / Accepted: 24 January 2022 /

Published online: 16 February 2022

(c) The Author(s) 2022

\begin{abstract}
The substrate temperature was investigated to broaden the applicability of controlling the morphology of polymeric fibers produced during the electrospinning process. A laboratory electrospinning setup was designed using a substrate heated in a temperature range of $25{ }^{\circ} \mathrm{C}$ to $100{ }^{\circ} \mathrm{C}$. A gelatin polymer was used as an example to obtain beads-free gelatin fibers by fixing the main electrospinning parameters. Based on XRD, FTIR, and DSC techniques, the electrospun gelatin fibers did not show any change in their chemical composition up to $100{ }^{\circ} \mathrm{C}$. Heating the substrate at $50{ }^{\circ} \mathrm{C}$ may be the best selection factor to obtain gelatin fibers; the fiber diameters experienced a significant decrease from $680 \pm 140 \mathrm{~nm}$ to $420 \pm 120 \mathrm{~nm}$ with increasing substrate temperature from 25 to $50{ }^{\circ} \mathrm{C}$, respectively. They showed stability of the diameter at $380 \pm 130 \mathrm{~nm}$ and $390 \pm 130 \mathrm{~nm}$ when increasing substrate temperatures from 75 to $100{ }^{\circ} \mathrm{C}$, respectively, with a significant variation in their diameter distribution. Therefore, this ability to control the electrospinning process using a heated substrate makes it promising for fabricating electrospun beads-free fibers of biopolymers such as gelatin for tissue engineering and drug delivery carriers.
\end{abstract}

Keywords Electrospinning $\cdot$ Substrate temperature $\cdot$ Gelatin $\cdot$ Nanofibers

\section{Introduction}

Biopolymer nanofibers and their fabrication methods include self-assembly, wet spinning, electrospinning, and solution blowing, which have become of great interest for their specific biomedical applications such as drug carriers and tissue engineering [1-6]. Electrospinning is interesting nanotechnology for producing nonwoven polymer fibers in the micron to nanometer range with a large surface area

Reda Morsy

r.morsy@science.tanta.edu.eg

1 Biophysics Lab, Physics Department, Faculty of Science, Tanta University, Tanta 31527, Egypt 
per mass ratio and high porosity [7-9]. Recently, electrospinning is used to design medical scaffolds for tissue engineering and tissue regeneration requiring controlled morphology [10-13]. The main feature of the electrospinning technique is its simple setup; its setup consists of three simple components: a high-voltage source, a capillary tube, and a grounded collector [14]. The electrospinning process is achieved by subjecting the dissolved polymers to high electrostatic forces to generate electric jets through a spinneret by drawing them until they evaporate and form continuous polymer filaments to be deposited on a grounded metal substrate $[15,16]$. Several forces control the fiber formation process include viscoelastic force, surface tension, electrostatic force, and gravitational force $[17,18]$. To improve the electrospinning process, the various parameters affecting the morphology of the electrospun fibers are classified into three categories: polymer solution parameters such as molecular weight, surface tension, and viscosity; parameters of processing conditions such as applied voltage, flow rate, needle diameter, and distance between tip and collector; and ambient parameters such as humidity, type of atmosphere, and external pressure [19-21]. However, all these many parameters, which can influence the electrospinning process, can be reduced to a limited number of independent parameters. For example, the non-independent parameters such as viscosity, evaporation rate, and conductivity depend on independent parameters such as polymer concentration, polymer type, and ambient parameters [22,23]. Although most electrospinning parameters have been studied in all the literature, none of these works investigated the effect of substrate temperature. Here, gelatin was chosen as a biopolymer for electrospinning because it is a commonly used biopolymer in many medical applications such as tissue engineering and drug delivery due to its biocompatible, bioactivity, and biodegradability [24, 25]. Unfortunately, the gelatin electrospinning process is subject to some challenges because aqueous gelatin solutions are not electrospinnable, and the morphology of the electrospun gelatin depends on the concentration $[26,27]$. Herein, this study aims to improve the effectiveness of a heated substrate on electrospun fiber. Besides, there is still a need to enhance the electrospinnability of gelatin fibers to produce fiber mats with suitable physicochemical properties for biomedical applications. Therefore, this study aimed to investigate the effect of substrate temperature on the morphology and composition of electrospun gelatin fibers. Gelatin was electrospun at different substrate temperatures under control of key electrospinning parameters such as the applied voltage, needle-collector distance, setup orientation, polymer concentration, and solution feeding rates. Conventional techniques are used to characterize gelatin fibrous such as X-ray diffraction (XRD), Fourier transformed spectroscopy (FTIR), differential scanning calorimetry (DSC), optical microscope, and scanning electron microscopy (SEM).

\section{Experimental sections}

\section{Materials}

Polymers of gelatin Type B from bovine skin (Approx. 225 Bloom) and glacial acetic acid (98\%, Al-Nasr, Egypt) were used without further treatment or 
purification. A gelatin solution $(300 \mathrm{mg} / \mathrm{mL})$ was prepared using acetic acid $(50 \%$ v/v) as a solvent. The gelatin solution was dissolved at $40{ }^{\circ} \mathrm{C}$ for $40 \mathrm{~min}$ and then was set to cool at room temperature.

\section{Aluminum plate substrate design}

A typical electrospinning setup coupled with heating and temperature maintenance accessories (Fig. 1) is used to maintain the substrate temperature at a fixed temperature. The substrate consists of a square aluminum plate of length $30 \mathrm{~cm}$. The heating element is made of wrapped nickel chrome wire that is clamped and homogeneously distributed under the substrate between two mica sheets $(30 \times 30 \mathrm{~cm})$. A calibrated digital thermocouple, stability \pm 0.5 to $1{ }^{\circ} \mathrm{C}$, was attached to the substrate to regulate and measure temperatures. Before the electrospinning process, the substrate was heated for $10 \mathrm{~min}$ at different temperatures $25^{\circ} \mathrm{C}, 50{ }^{\circ} \mathrm{C}, 75^{\circ} \mathrm{C}$, and $100{ }^{\circ} \mathrm{C}$.

\section{Electrospinning process}

Figure 1 shows a schematic diagram of the laboratory-designed electrospinning setup and the heated substrate. The electrospinning setup consists of a high-DC voltage adjustable power supply (Goldmann 40K), a syringe pump (KD Scientific 100 series), a polyethylene syringe, a stainless-steel needle connected to a positive supply, and a grounded aluminum plate substrate. The gelatin solution, $300 \mathrm{mg} / \mathrm{mL}$, was inserted into a 10-mL syringe connected to a rubber tube (long: $50 \mathrm{~cm}$, internal diameter: $2 \mathrm{~mm}$ ) ended with a metal needle placed vertically to the collecting substrate plate. The main parameters values were selected to produce consistent electrospun beads-free gelatin fibers: applied voltage at $15 \mathrm{kV}$, the distance between needle and collector at $12 \mathrm{~cm}$, and the solution flow rate at $1.2 \mathrm{~mL} / \mathrm{hr}$. The substrate temperatures were set at $25^{\circ} \mathrm{C}, 50^{\circ} \mathrm{C}, 75^{\circ} \mathrm{C}$, and $100{ }^{\circ} \mathrm{C}$.

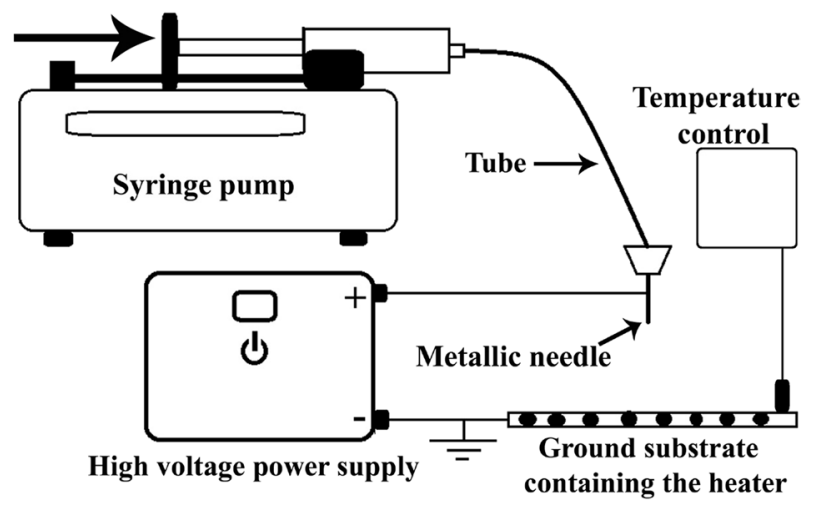

Fig. 1 Schematic diagram of the electrospinning setup with a heated substrate 


\section{Characterization methods}

To confirm the best selecting of the previous independent electrospinning parameters, a typical optical microscope (OPTIKA with Digital Imaging, Italy) was used to image the number of electrospun gelatin fibers for 5 and $25 \mathrm{~s}$ on a glass slide. The crystallization structure of the electrospun gelatin fibers was characterized by X-ray diffraction (XRD) analysis using a GNR-APD 20000 pro, H423-vertical diffractometer. The chemical structure and functional groups of electrospun gelatin were confirmed by Fourier Transform Infrared Spectroscopy (FTIR) using a Perkin-Elmer-1600 spectrophotometer. FTIR spectra were recorded in the range from 400 to $4000 \mathrm{~cm}^{-1}$. Differential scanning calorimetry (DSC: TA Instruments-SDT Q600) was used to analyze the thermal properties of the electrospun gelatin fibers. All samples were heated from 25 to $200{ }^{\circ} \mathrm{C}$ at a heating rate of $15^{\circ} \mathrm{C} / \mathrm{min}$ under a constant flow of a nitrogen atmosphere. The morphology and microstructures of the electrospun gelatin fibers samples were examined by scanning electron microscopy (SEM) using a JEOL 6400 electron microscope. The average fiber diameter, distribution, and standard deviation for 50 arbitrary measured fibers were obtained by processing SEM images with the Image $\mathbf{J}$ software.

\section{Results and discussion}

\section{Selection of electrospinning parameters}

Obtaining optimal electrospun gelatin fibers has been influenced by several parameters that should be adjusted and fixed in this study to obtain beads-free fibers. The electrospinning process was carried out as described in previous sections, with a gelatin solution fed to a vertical needle and the application of a direct electric field. At room temperature, before changing the substrate temperatures, the independent electrospinning parameters had to be optimized. Optimizing these parameters is a crucial step to confirm the production of consistent electrospun beads-free gelatin fibers. As aforementioned, the independent electrospinning parameters were set as outlined in Table 1.

Figure 2 shows the images obtained by the optical microscope for gelatin fibers electrospun on a glass slide for $5 \mathrm{~s}$ (Fig. 2a) and $25 \mathrm{~s}$ (Fig. 2b) before the study to

Table 1 Electrospinning parameters of electrospun beads-free gelatin fibers

\begin{tabular}{llc}
\hline Parameter & Value & References \\
\hline Setup orientation & Vertical & [28-34] \\
Substrate temperature & $25^{\circ} \mathrm{C}$ & \\
Voltage & $15 \mathrm{kV}$ & \\
Needle-collector separation & $12 \mathrm{~cm}$ & \\
Concentration of gelatin solution & $300 \mathrm{mg} / \mathrm{mL}$ & \\
Polymer feed rates & $1.2 \mathrm{~mL} / \mathrm{h}$ & \\
\hline
\end{tabular}



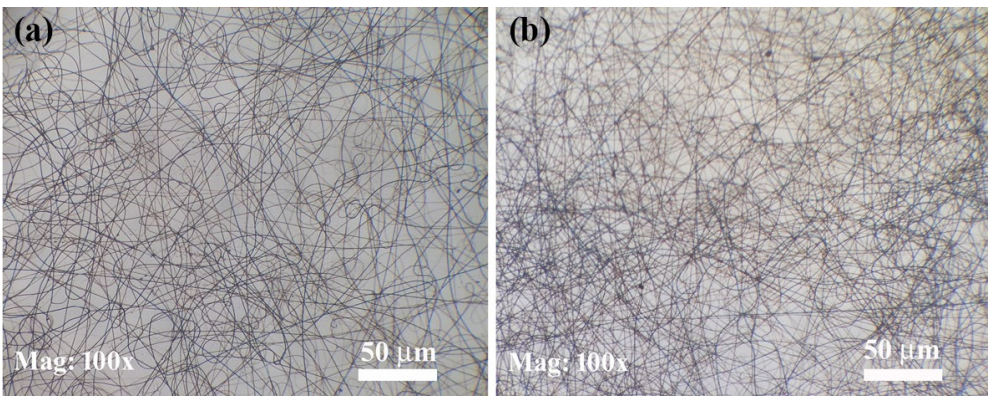

Fig. 2 Optical microscope images (magnification: 100x) of the number of gelatin fibers electrospun on a glass slide for $\mathbf{a} 5 \mathrm{~s}$ and $\mathbf{b} 25 \mathrm{~s}$

test the selected optimizing parameters. The results confirmed the formation of uniform electrospun fiber morphology with beads-free.

\section{Structural analysis}

XRD analysis was used to investigate the effect of substrate heating on the crystalline structure of electrospun gelatin fibers fabricated at substrate temperatures of 25 , 50, 75, and $100{ }^{\circ} \mathrm{C}$, respectively. As apparent from Fig. 3, the diffraction patterns showed an amorphous nature of the electrospun gelatin fibers with the appearance of two broadened humps around 2-theta equals $4^{\circ}$ and $19^{\circ}$. The formation of these crystalline structures is due to the secondary structure of gelatin, triple helix, and polypeptide strands $[18,35]$. Samples at temperatures up to $100{ }^{\circ} \mathrm{C}$ had similar patterns. By increasing the substrate temperatures up to $100{ }^{\circ} \mathrm{C}$, the broadened humps

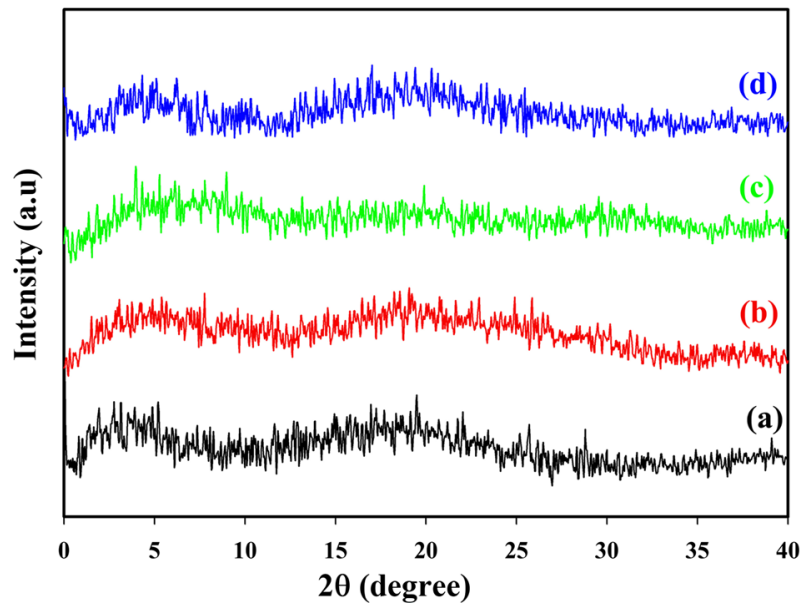

Fig. 3 SEM images (magnification: $3500 \times$ ) and size distribution of electrospun gelatin fibers at different substrate temperatures: $\mathbf{a} 25^{\circ} \mathrm{C}, \mathbf{b} 50{ }^{\circ} \mathrm{C}$, c $75^{\circ} \mathrm{C}$, and d $100{ }^{\circ} \mathrm{C}$ 
around $2 \theta=4^{\circ}$ and $19^{\circ}$ showed no difference or sharpening. The XRD results revealed that the polymorphic behavior of electrospun gelatin fibers is not subject to variation when the substrate temperatures are changed.

\section{FTIR Spectra of gelatin fibers}

FTIR analysis was used to investigate the functional groups and structural modifications of electrospun gelatin fibers fabricated at substrate temperatures of 25, 50, 75, and $100{ }^{\circ} \mathrm{C}$, respectively. The FTIR spectra (Fig. 4) showed that all samples had exhibited the identical characteristic vibrational bands belonging to the electrospun gelatin fibers: amide I, amide II, amide III, and amide B. The peak that appeared at $1645 \mathrm{~cm}^{-1}$ can be assigned to stretching vibration of $\mathrm{C}=\mathrm{O}$ belonging to amide I, while those at $1540 \mathrm{~cm}^{-1}$ can be assigned to $\mathrm{N}-\mathrm{H}$ bending vibration of amide II [10]. The peaks that appeared at 2940 and $3280 \mathrm{~cm}^{-1}$ are assigned to the $\mathrm{C}-\mathrm{H}$ stretching vibration of amide $\mathrm{B}$ and $\mathrm{N}-\mathrm{H}$ stretching vibration of amide $\mathrm{A}$, respectively $[13,25]$. For the $\mathrm{N}-\mathrm{H}$ bending vibration of the amide III, the spectra showed a peak at $1240 \mathrm{~cm}^{-1}$ [26]. The results indicated that increasing the substrate temperatures to $100{ }^{\circ} \mathrm{C}$ did not affect the absorption bands, confirming the absence of chemical structural modifications of the electrospun gelatin fibers.

\section{Thermal properties of gelatin fibers}

Figure 5 shows the DSC thermogram of the electrospun gelatin fibers fabricated at substrate temperatures of $25,50,75$, and $100{ }^{\circ} \mathrm{C}$, respectively. The samples exhibited a single endothermic peak above $100{ }^{\circ} \mathrm{C}$ that attributed to the melting temperature of gelatin [35]. This peak results from the breakage of hydrogen bonds of

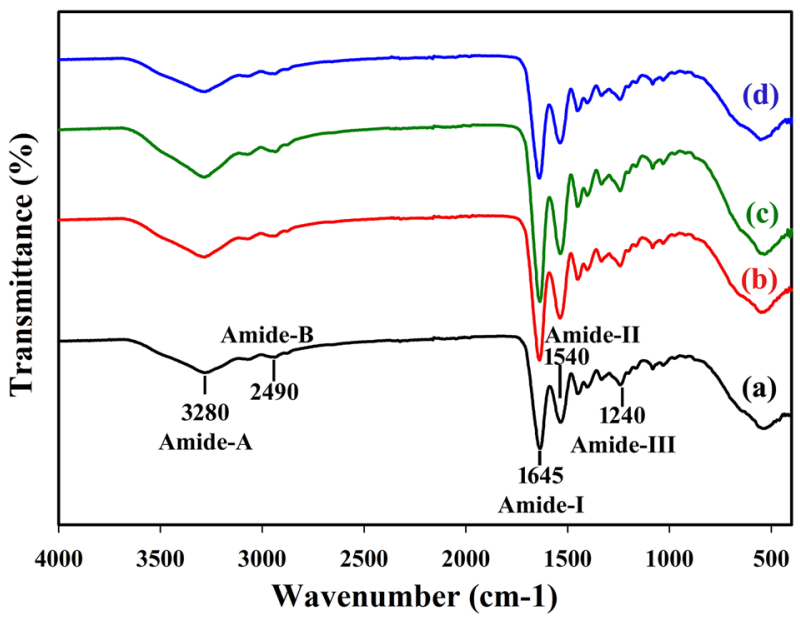

Fig. 4 XRD patterns of electrospun gelatin fibers at different substrate temperatures: $\mathbf{a} 25^{\circ} \mathrm{C}, \mathbf{b} 50{ }^{\circ} \mathrm{C}, \mathbf{c}$ $75^{\circ} \mathrm{C}$, and $\mathbf{d} 100{ }^{\circ} \mathrm{C}$ 


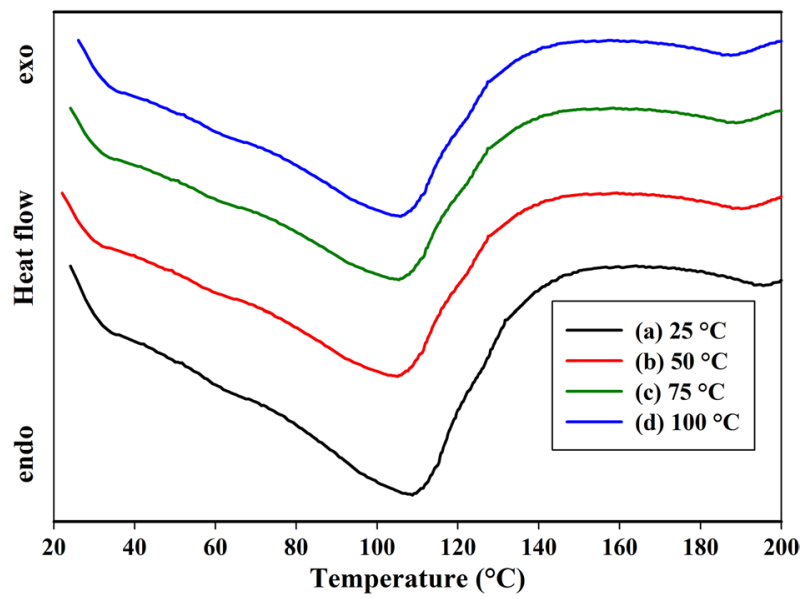

Fig. 5 FTIR spectra of electrospun gelatin fibers at different substrate temperatures: a $25{ }^{\circ} \mathrm{C}, \mathbf{b} 50{ }^{\circ} \mathrm{C}, \mathbf{c}$ $75^{\circ} \mathrm{C}$, and $\mathbf{d} 100{ }^{\circ} \mathrm{C}$

the triple-helix structure and its transition into the values coil-like structure [36]. DSC curves showed that the diameter of the electrospun gelatin fibers significantly influenced the endothermic peaks. The endothermic peak at $108.5^{\circ} \mathrm{C}$ (fibers diameter $\sim 680 \mathrm{~nm}$ spun at a substrate temperature of $25^{\circ} \mathrm{C}$ ) shifted to about $106^{\circ} \mathrm{C}$ for spun fibers at substrate temperatures above $50{ }^{\circ} \mathrm{C}$. Above $50{ }^{\circ} \mathrm{C}$, the endothermic peaks did not differ significantly due to the stability of the electrospun gelatin fiber diameters which also indicate no effect on the electrospinnability of the gelatin working solutions [37, 38]. This behavior resulted from acetic acid diffusion in the microfiber that became more difficult for thicker ones. Also, acetic acid evaporation is responsible for the peak broadening between 40 and $130{ }^{\circ} \mathrm{C}$ [39]. The proximity of the melting temperature of gelatin, $105-108{ }^{\circ} \mathrm{C}$, to the boiling point of acetic acid, $118{ }^{\circ} \mathrm{C}$, can cause an overlapping between them due to the amount of acetic acid inside the samples [40]. The results showed a shift in the endothermic peaks to lower temperatures when the diameter of the fibers was smaller. This behavior for smaller fiber diameters can be explained by easily solvent evaporation due to the shorter diffusion paths. These results together with the results of X-ray and FTIR analysis confirm that increasing the substrate temperatures up to $100{ }^{\circ} \mathrm{C}$ did not affect the structural or chemical composition of the electrospun gelatin fibers, confirming the absence of chemical structural modifications on them.

\section{Structural morphologies}

SEM analysis was used to investigate the influence of substrate temperatures on the topological and morphological features of electrospun gelatin fibers fabricated at substrate temperatures of $25,50,75$, and $100{ }^{\circ} \mathrm{C}$, respectively. The electrospun fibers were collected in random orientations so that the diameters of electrospun fibers were measured in relative distributions. SEM images, Fig. 6, 

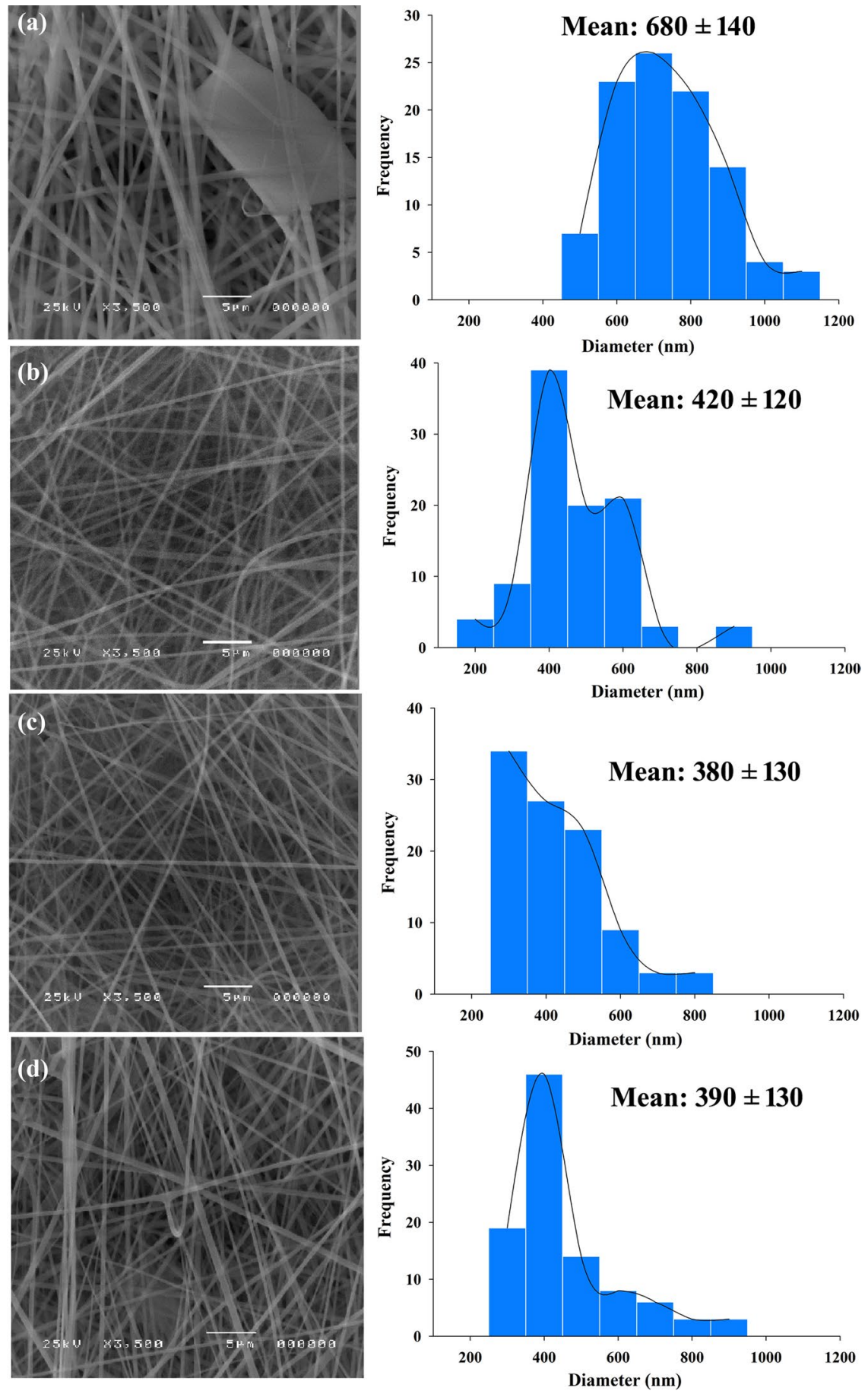

Fig. 6 DSC curves of electrospun gelatin fibers at different substrate temperatures: a $25{ }^{\circ} \mathrm{C}$, b $50{ }^{\circ} \mathrm{C}$, c $75^{\circ} \mathrm{C}$, and $\mathbf{d} 100{ }^{\circ} \mathrm{C}$ 
show that all electrospun gelatin fibers have a regular morphology free of beads defects. The increase in the substrate temperatures did not change the surface of the fibers; the fibers had smooth surfaces without the formation of bead defects. The results exhibited that heating the substrate induces a significant reduction in the diameter of electrospun gelatin fibers. Figure 4 shows the differences in the statistical results between the four samples. The results showed that increasing the substrate temperature from $25{ }^{\circ} \mathrm{C}$, at room temperature, to $50{ }^{\circ} \mathrm{C}$ led to a significant decrease in the fiber diameter from $680 \pm 140 \mathrm{~nm}$ to $420 \pm 120 \mathrm{~nm}$, respectively. However, increasing the substrate temperature above $50{ }^{\circ} \mathrm{C}$ did not affect the diameter of the electrospun gelatin fibers as the mean diameters were $380 \pm 130 \mathrm{~nm}$ and $390 \pm 130 \mathrm{~nm}$ for the substrate temperatures at $75{ }^{\circ} \mathrm{C}$ and $100{ }^{\circ} \mathrm{C}$, respectively. The increase in the substrate temperatures from 50 to $100{ }^{\circ} \mathrm{C}$ did not significantly affect the diameter of the electrospinning gelatin fibers. However, the samples show a significant variation in their diameter distributions (Fig. 6e, f). The increase in the substrate temperatures from 50 to $100{ }^{\circ} \mathrm{C}$ had no effects on the Electrospinnability of the gelatin working solution, which can be explained by the ability of the heated substrate to cause a thermal zone surrounding it where the jet accelerated into this zone may undergo an increased viscosity and constant evaporation of the solvent.

\section{Conclusion}

This work investigated the influence of substrate temperatures, as an electrospinning parameter, on the structure and morphology of electrospun gelatin fibers. The substrate temperatures were varied in the temperature range of $25{ }^{\circ} \mathrm{C}$ to $100{ }^{\circ} \mathrm{C}$ to produce beads-free gelatin. The main electrospinning parameters were fixed; they include applied voltage, spinning distance, polymer concentration, polymer, and feed rates. Increasing the substrate temperatures up to $100{ }^{\circ} \mathrm{C}$ did not affect the composition of gelatin fibers. The results exhibited that the diameters of the fibers decrease from $680 \pm 140 \mathrm{~nm}$ to $420 \pm 120 \mathrm{~nm}$ with increasing substrate temperature from $25{ }^{\circ} \mathrm{C}$ to $50{ }^{\circ} \mathrm{C}$, respectively. Raising the substrate temperatures from $50{ }^{\circ} \mathrm{C}$ to $100{ }^{\circ} \mathrm{C}$ did not affect the average diameter of the gelatin fibers, while it significantly affected their diameter distribution. The results showed that heating the substrate to $50{ }^{\circ} \mathrm{C}$ may be a good critical selection factor for obtaining microfibers. This attempt to optimize the effect of heating the substrate on the electrospun gelatin fibers provided satisfactory results. This possibility will make the approach of electrospinning gelatin with heated substrate promised for fabricating electrospun fibrous mats for tissue engineering and drug delivery carriers.

Funding Open access funding provided by The Science, Technology and Innovation Funding Authority (STDF) in cooperation with The EgyptianKnowledge Bank (EKB). 


\section{Declarations}

Conflict of interest There are no conflicts to declare in this study among authors.

Open Access This article is licensed under a Creative Commons Attribution 4.0 International License, which permits use, sharing, adaptation, distribution and reproduction in any medium or format, as long as you give appropriate credit to the original author(s) and the source, provide a link to the Creative Commons licence, and indicate if changes were made. The images or other third party material in this article are included in the article's Creative Commons licence, unless indicated otherwise in a credit line to the material. If material is not included in the article's Creative Commons licence and your intended use is not permitted by statutory regulation or exceeds the permitted use, you will need to obtain permission directly from the copyright holder. To view a copy of this licence, visit http://creativecommons.org/licen ses/by/4.0/.

\section{References}

1. Kakoria A, Sinha-Ray S (2018) A review on biopolymer-based fibers via electrospinning and solution blowing and their applications. Fibers 6(3):45

2. Cui H, Webber MJ, Stupp SI (2010) Self-assembly of peptide amphiphiles: From molecules to nanostructures to biomaterials. Biopolymers 94(1):1-8

3. Meier C, Welland ME (2011) Wet-spinning of amyloid protein nanofibers into multifunctional high-performance biofibers. Biomacromol 12(10):3453-3459

4. Daglar O, Altinkok C, Acik G, Durmaz H (2020) Electrospinning of poly (1,4-Cyclohexanedimethylene Acetylene Dicarboxylate): Study on the morphology, wettability, thermal and biodegradation behaviors. Macromol Chem Phys 221(23):2000310

5. Khansari S, Sinha-Ray S, Yarin AL, Pourdeyhimi B (2013) Biopolymer-based nanofiber mats and their mechanical characterization. Ind Eng Chem Res 52(43):15104-15113

6. Schiffman JD, Schauer CL (2008) A review: electrospinning of biopolymer nanofibers and their applications. Polym Rev 48(2):317-352

7. Chen S, Li R, Li X, Xie J (2018) Electrospinning: an enabling nanotechnology platform for drug delivery and regenerative medicine. Adv Drug Deliv Rev 132:188-213

8. Kchaou M, Alquraish M, Abuhasel K, Abdullah A, Ali AA (2021) Electrospun nanofibrous scaffolds: review of current progress in the properties and manufacturing process and possible applications for COVID-19. Polymers 13(6):916

9. Yang G, Li X, He Y, Ma J, Ni G, Zhou S (2018) From nano to micro to macro: Electrospun hierarchically structured polymeric fibers for biomedical applications. Prog Polym Sci 81:80-113

10. Morsy R, Hosny M, Reicha F, Elnimr T (2017) Developing and physicochemical evaluation of cross-linked electrospun gelatin-glycerol nanofibrous membranes for medical applications. J Mol Struct 1135:222-227

11. Rahmati M, Mills DK, Urbanska AM, Saeb MR, Venugopal JR, Ramakrishna S, Mozafari M (2021) Electrospinning for tissue engineering applications. Prog Mater Sci 117:100721

12. Acik G (2021) Fabrication of polypropylene fibers possessing quaternized ammonium salt based on the combination of CuAAC click chemistry and electrospinning. React Funct Polym 168:105035

13. Morsy R, Hosny M, Reicha F, Elnimr T (2016) Development and characterization of multifunctional electrospun ferric oxide-gelatin-glycerol nanofibrous mat for wound dressing applications. Fibers Polym 17(12):2014-2019

14. Angammana C, Jayaram S (2016) Fundamentals of electrospinning and processing technologies. Part Sci Technol 34(1):72-82

15. Rutledge GC, Fridrikh SV (2007) Formation of fibers by electrospinning. Adv Drug Deliv Rev 59(14):1384-1391

16. Wang C, Wang J, Zeng L, Qiao Z, Liu X, Liu H, Zhang J, Ding J (2019) Fabrication of electrospun polymer nanofibers with diverse morphologies. Molecules 24(5):834 
17. Kong CS, Yoo WS, Jo NG, Kim HS (2010) Electrospinning mechanism for producing nanoscale polymer fibers. J Macromol Sci B 49(1):122-131

18. Padron S, Fuentes A, Caruntu D, Lozano K (2013) Experimental study of nanofiber production through forcespinning. J Appl Phys 113(2):024318

19. Jacobs V, Anandjiwala RD, Maaza M (2010) The influence of electrospinning parameters on the structural morphology and diameter of electrospun nanofibers. J Appl Polym Sci 115(5):3130-3136

20. Tripatanasuwan S, Zhong Z, Reneker DH (2007) Effect of evaporation and solidification of the charged jet in electrospinning of poly(ethylene oxide) aqueous solution. Polymer 48(19):5742-5746

21. Matabola KP, Moutloali RM (2013) The influence of electrospinning parameters on the morphology and diameter of poly(vinyledene fluoride) nanofibers- effect of sodium chloride. J Mater Sci 48:5475-5482

22. Cengiz-Çallığlu F, Jirsak O, Dayik M (2013) Investigation into the relationships between independent and dependent parameters in roller electrospinning of polyurethane. Text Res J 83(7):718-729

23. Jirsak O, Petrik S (2012) Recent advances in nanofibre technology: needleless electrospinning. Int J Nanotechnol 9(8-9):836-845

24. Dong Z, Meng X, Yang W, Zhang J, Sun P, Zhang H, Fang X, Wang DA, Fan C (2021) Progress of gelatin-based microspheres (GMSs) as delivery vehicles of drug and cell. Mater Sci Eng C 122:111949

25. Morsy R (2016) Thermal treatment of gelatin solution improves the quality of electrospun gelatin fibrous mats for medical applications. Rom J Biophys 26(2)

26. Morsy R, Hosny M, Reicha F, Elnimr T (2017) Developing a potential antibacterial long-term degradable electrospun gelatin-based composites mats for wound dressing applications. React Funct Polym 114:8-12

27. Erencia M, Cano F, Tornero JA, Fernandes MM, Tzanov T, Macanas J, Carillo F (2015) Electrospinning of gelatin fibers using solutions with low acetic acid concentration: effect of solvent composition on both diameter of electrospun fibers and cytotoxicity. J Appl Polym Sci 132(25):42115

28. Chen HC, Jao WC, Yang MC (2009) Characterization of gelatin nanofibers electrospun using ethanol/formic acid/water as a solvent. Polym Adv Technol 20(2):98-103

29. Lakshminarayanan R, Sridhar R, Loh XJ, Nandhakumar M, Barathi VA, Kalaipriya M, Kwan JL, Liu SP, Beuerman RW, Ramakrishna S (2014) Interaction of gelatin with polyenes modulates antifungal activity and biocompatibility of electrospun fiber mats. Int J Nanomed 9:2439

30. Rujitanaroj PO, Pimpha N, Supaphol P (2008) Wound-dressing materials with antibacterial activity from electrospun gelatin fiber mats containing silver nanoparticles. Polymer 49(21):4723-4732

31. Chen DW, Liao JY, Liu SJ, Chan EC (2012) Novel biodegradable sandwich-structured nanofibrous drug-eluting membranes for repair of infected wounds: an in vitro and in vivo study. Int J Nanomed 7:763

32. Hajiali H, Shahgasempour S, Naimi-Jamal MR, Peirovi H (2011) Electrospun PGA/gelatin nanofibrous scaffolds and their potential application in vascular tissue engineering. Int J Nanomed 6:2133

33. Joy J, Pereira J, Aid-Launais R, Pavon-Djavid G, Ray AR, Letourneur D, Meddahi-Pellé A, Gupta B (2018) Gelatin-oxidized carboxymethyl cellulose blend based tubular electrospun scaffold for vascular tissue engineering. Int J Biol Macromol 107:1922-1935

34. Moon S, Farris RJ (2009) Electrospinning of heated gelatin-sodium alginate-water solutions. Polym Eng Sci 49(8):1616-1620

35. Pawde SM, Deshmukh K, Parab S (2008) Preparation and characterization of poly (vinyl alcohol) and gelatin blend films. J Appl Polym Sci 109(2):1328-1337

36. Apostolov AA, Fakirov S, Vassileva E, Patil RD, Mark JE (1999) DSC and TGA studies of the behavior of water in native and crosslinked gelatin. J Appl Polym Sci 71(3):465-470

37. Yakimets I, Paes SS, Wellner N, Smith AC, Wilson RH, Mitchell JR (2007) Effect of water content on the structural reorganization and elastic properties of biopolymer films: a comparative study. Biomacromol 8(5):1710-1722

38. Ki CS, Baek DH, Gang KD, Lee KH, Um IC, Park YH (2005) Characterization of gelatin nanofiber prepared from gelatin-formic acid solution. Polymer 46(14):5094-5102

39. Schubnell M, Schawe JE (2001) Quantitative determination of the specific heat and the glass transition of moist samples by temperature modulated differential scanning calorimetry. Int J Pharm 217(1-2):173-181 
40. Erencia M, Cano F, Tornero JA, Fernandes MM, Tzanov T, Macanás J, Carrillo F (2015) Electrospinning of gelatin fibersusing solutions with low acetic acid concentration: Effect of solvent composition on both diameter of electrospun fibers andcytotoxicity. J Appl Polym Sci 132(25)

Publisher's Note Springer Nature remains neutral with regard to jurisdictional claims in published maps and institutional affiliations. 